\title{
Factors Preventing Technical Colleges and Universities from Cultivating Foreign Language Talents
}

\author{
Yanlin Li ${ }^{*}$, Mingfeng Yang ${ }^{2}$ \\ ${ }^{1}$ Department of Humanities, Xiangtan Institute of Technology, Xiangtan 411105, China \\ ${ }^{2}$ School of Foreign Languages, Central South University, Changsha 410083, China \\ *Corresponding author: Yanlin Li, cstdxy2008@126.com
}

\begin{abstract}
This article discusses about the cultivation of foreign language talents, through which it can be appreciated that the emphasis is to be laid on improving their comprehensive qualities. Only in this way can foreign language talents adapt to the needs of the market, integrate into the ranks of technical personnel in the field of engineering, and be warmly welcomed by employers or employing units. Nevertheless, in order to achieve this aim, three factors should be overcome to avoid the hindrance faced by technical colleges and universities from cultivating foreign language talents with comprehensive qualities. This article probes into the three negative factors: first, students are not fluent in their mother tongue; second, foreign language majors lack basic knowledge of science and technology so much so that they are not able to do well in such translation; third, they lack the ability to perform simultaneous interpretation Simultaneous interpreting. In regard to those factors, this article then provides several suggestions as countermeasures to those three negative factors, so as to cultivate talents that can satisfy the needs of the market.
\end{abstract}

Keywords: Factors; Cultivation of foreign language talents; Technical colleges and university

Publication date: December 2021; Online publication: December 23, 2021

\section{Introduction}

With the economic globalization, people have quickened their steps in many fields, so as to be in line with international requests and standards. Moreover, many countries have been trying to unify their national higher education entrance examinations. For instance, one of the Asian countries has been making effort in this matter. As a result, the market mechanism of this country is becoming more ideal, and its market orientation is more obvious with increasingly high degree of marketing. Therefore, the main issue for students in technical colleges and universities will be on how they can improve their own qualities, adapt to the needs of market, seize the opportunity, and meet the challenges.

As far as the students from the departments or schools of foreign languages in technical colleges and universities are concerned, it is necessary for them to further strengthen the cultivation and development of their own qualities because foreign language talents of the society should have high qualities in today's world. According to a survey, most foreign language majors have a single career. It is relatively difficult for them to adapt to the requirements of the market and base themselves in the current fierce competition. Furthermore, it is difficult for them to grow in their respective positions in becoming experts or somebody who would make great achievements and contribute to the society. What then are the negative factors that should be smoothed away in the cultivation of foreign language talents in technical colleges and universities? According to our humble opinion, they are the three factors that should be considered. 


\section{Students' poor proficiency in their mother tongues}

Judging from a long period of foreign language teaching pattern in the past, as the majority of both the teachers and students have confined their minds to an old professional circle, inevitably they lay undue emphasis on learning foreign languages well rather than their own mother tongues. In China, even if modern Chinese is being taught, students rarely pay any attention to this course because they tend to perceive that this course has nothing to do with their future professions but purely as a behaviour of carrying coals to Newcastle. As a result, most foreign language students look down upon this kind of education. In some places, it has even become a deeply rooted chronic problem and a vicious circle, thus affecting the highquality cultivation and training of foreign language talents or professionals.

As a matter of fact, the occupational demand for qualified personnel is high, and the standards that should be followed are artificial and relative. If the standards are outside of this category, they are endless. A famous character once stated, "Those who cannot do better than the people today cannot be called talents, and the ones whose learning is not more than that of the ancient people are of no knowledge ${ }^{[1]}$." It can be seen that it is not an easy thing to be one of ability and rich knowledge. For example, after graduation, students from technical colleges and universities would work either in companies or in middle schools, colleges, or universities. As companies are more market-oriented and meet the challenges of the market, those who work in companies have to face the market and meet the challenges faced by these companies while shouldering greater responsibilities. Stopping at nothing, they have to give their all to translate science and technology into productive forces, money, and materials; however, it is often the case that they are unable to undertake this important task and work independently. As far as teaching is concerned, there are many difficulties and worries in this field. Imparting knowledge and educating people are not just by words but by action. Moreover, they have to face a lot of people, including parents, the leadership of the company, a great number of pupils or students, staffs who are receiving training, the society, and the counterparts in the industry. They have to accept the test of the society, its people, and that of the market. There is no doubt that teachers are hardworking gardeners and the soul engineers of mankind, whose small ink bottle is filled with spring, autumn, the sea, the blue sky, the universe, and everything else related to human beings. This indicates that teachers must be truly knowledgeable experts. Teachers must make every effort to teach their students everything they know, guide the students through the labyrinth of their studies, and encourage them to be better students than they were rather than just being satisfied with their present situation of following the footsteps of others by repeating what others have said, mirroring what others have done, or being artisans who can only make a living. If one desires to be a talent who can contribute to the society and work independently at the forefront, one should not only confine his or her goals to a specific major or established occupational ring but instead, try to find his or her own weak points and then mend them by learning the strong points from others and focusing on preventing single knowledge learning. In this century, many long-lived experts and professors are worried about the ability and standard of foreign language majors from technical colleges and universities in using their mother tongue. They believe that the society must be developed, and culture must be exchanged, in the process of which the essence of the native culture must not only be an output, but also introduced and absorbed. This process is complex; the task is arduous, full of ups and downs. The translation of Chinese and foreign cultures, including the introduction of foreign ones, require translators to have a solid foundation with good understanding and expression. For example, a person from China would most likely think in his or her mother tongue, and when that person translates famous ancient Chinese works, the knowledge about Chinese classics should be on his or her fingertips. On the other hand, when translating foreign literary works, he or she should have a relatively strong ability of expressing the contents in Chinese; otherwise, any interpretation or translation would be inutile. It is of no surprise to what has been mentioned by Gechuan Qian: "A translator must reach a certain level of perfection in two languages, which seems to be the minimum requirement; 
otherwise, the translator would not be able to perform any translation work. However, the degree of being proficient in each of the two languages is different; that is, the person must be critical in judging the knowledge of the foreign language but emphasize on the practical application of the native language's knowledge ${ }^{[2]}$." To be more precise, only a poet can translate a poem well, only those who are well-versed in ancient Chinese can translate Chinese classics well, and only scholars who are familiar with a certain prose can translate it well. As far as all the translators from modern times to the present are concerned, they are those who practise in their native language. Therefore, courses of ancient Chinese and Chinese writing should be taught in technical colleges and universities (these courses can also be included in extracurricular activities). Other than that, translation courses can be taught to students, who are interested in English or other languages, from the department of Chinese or the school of liberal arts in technical colleges and universities. Perhaps in this manner, there would be more practical talents and translators in the future talent market. Only in this way, students can be guided to make full use of the advantages existing in their native language and foreign languages as well as overcome the difficulty of the lack of proficiency in their native language, thus prospering the market economy and translational cause.

\section{Inept translation skills in science and technology among foreign language majors}

It is known to all that after China's entry into World Trade Organization (WTO), the translation of science and technology has become extremely important. Situations have shown that China is in need of talents who can engage in the translation of science and technology. Firstly, the traditional enrolment style of technical colleges and universities conditions that students who are interested to major in foreign languages can only be recruited from third-year liberal arts graduates of senior middle schools. Second, international exchanges of science and technology are carried out in full swing, thus causing foreign language graduates from technical colleges and universities to worry about opportunities in the professional field after graduation. Lastly, experts who are engaged in the translation of science and technology are relatively few in the foreign language department in technical colleges or universities. There are times when not a single expert in the field can be found in those departments or schools. Therefore, technical colleges or universities are lacking the prerequisite to recruit science and technology translation majors and to offer this course. From the translation course offered by departments or schools in most of the present technical colleges or universities, the course of science and technology translation has not been offered yet, students are still using textbooks related to the translation of social science, and teachers who can engage in science and technology translation are few in numbers, so students majoring in foreign languages are unable to gain access to the translation of science and technology; thus, the need of the society for this kind of talent is not satisfied.

In order to change the current training mode of translation talents and the present situation, which lacks translation talents, great efforts must be made in terms of the course setting, enrolment, teachers' training, and construction of textbooks. A suggestion to this is that social sciences translation and natural sciences translation courses can be taught in foreign language departments or schools in technical colleges and universities. In addition, graduates from senior middle schools who performed well in both English and natural sciences courses can be suitably admitted to these departments and schools to learn foreign languages. Meanwhile, teachers' training and teaching materials can be closely followed. There are no issues in regard to this as the editorial board of Chinese Translators Journal, as the guiding unit in the translation circle, can make full use of its own advantages to organize authoritative trainings for teachers and the compilation of textbooks. 


\section{Students lack the ability to perform simultaneous interpretation}

Simultaneous interpretation is an art which requires learners to practice and is of great help to people in cultivating a new generation of foreign language talents with high qualities in the 21 st century. However, simultaneous interpreting is only taught in selected first-class universities. In other foreign language departments or schools in technical colleges and universities, many students and teachers have never thought about it or accumulated game experience. Therefore, when large business and trade negotiations with foreigners are held, which require simultaneous interpreting talents, it is an obstacle for the organizers as they hastily try to find interpreters who are able to perform simultaneous interpretation. In the case where an interpreter who is unfamiliar with the art is recruited, he or she might lack the ability, thus failing to control the interpreting speed and in grasping the interpreting keywords, either breathlessly, without conveying the main idea, or without making the necessary points. Ironically, many mistakes can then be seen in the interpretation, including inappropriate emotions. To make the long story short, the interpreter would be deemed unsuccessful, and thus the only way out is to turn to specialized interpreting institutions for help. When interpreters cannot be found, people may say, "Foreign language teachers are increasing in number, but interpreters are becoming rare." This statement truly harms the image of foreign language teachers in technical colleges and universities as well as the honour of foreign language majors. However, this shows that the teaching reform of foreign languages in technical colleges and universities must be deepened and strengthened, and their curriculum should be modified in line with the needs of the society and the market. The cultivation of foreign language talents must be of high quality and in line with the market. At the same time, the traditional teaching should be changed to an open teaching, transforming classroom teachings in a way that students can learn from the society and the market. This would eventually prevent embarrassment and the difficulty in looking for interpreters. Nowadays, it is also difficult to look for a specialized interpreting company, let alone an interpreter there. Even if there is a specialized translation company, it is often named, "XXX Material Translation Company," where one would find translators who can only perform translations without knowledge in interpreting work.

There is a talent who is able to interpret. Somehow, a state-owned unit, located hundreds of kilometres away, received news about this talent. The unit hired the talent, and the talent was treated well by the unit. From this, it can be appreciated that talents who are able to interpret are popular among units and are badly needed by the society as well as the market. Even in other fields, there are very few interpreters. This may make people feel that although they have made every effort to look for these talents, they are still unable to find them as if wearing out iron shoes in a fruitless search. This also indicates that the focus has not been on the cultivation of talents who are able to interpret. It is necessary to accumulate experience and establish an effective system of cultivation. At the same time, there is very minimal progress in its teaching reform without a sense of mission of the time. From what has been revealed in the current pattern of foreign language teaching in foreign language departments and schools in several technical colleges and universities, people generally follow the past modes of foreign language teaching, which have been established. Although oral English is being taught, simultaneous interpreting has not been given significance. There are people who think that oral English classes are equal to simultaneous interpreting classes and that if one is excellent in speaking English, he or she would excel in simultaneous interpreting. It is incorrect to think that oral English classes can replace simultaneous interpreting classes. In essence, both oral English classes and simultaneous interpreting classes stress on oral expression, but in oral English classes, students are in a relatively relaxed environment without the restriction of translating two different languages through a third party and the time constraint of each sentence; in simultaneous interpreting classes, which are under the category of interpreting classes, from the very beginning, students would tend to feel a sort of negotiating occasion of foreign affairs or foreign trade. During interpreting, it is common that the atmosphere is tense, and the interpreter is assumed as the third party, who must be extremely careful 
not to arbitrarily change the meaning of the original content from each party but express what is correctly understood without any error while taking logical and grammatical responsibilities for the effect of the talks, dialogues, or negotiations when interpreting from one language to another. Therefore, simultaneous interpreting should be instructionally taught in foreign language departments and schools in technical colleges and universities, so that the students' weak point in their ability to perform simultaneous interpreting can be smoothed away, thus improving their foreign language skills as well as unceasingly broadening and creating employment opportunities.

\section{Conclusion}

It is not easy to cultivate talents. It is necessary to excel at both, finding talents and cultivating them. As the old Chinese saying goes, "It takes ten years to grow trees but a hundred years to nurture a person." However, at times, when it is urgent to nurture people, is it then possible to subtract ninety from the hundred years and nurture people in ten (years)? The fact is that it is not possible to accomplish it in one day but it is a long-term project - a project of vital and lasting importance and even more. The cultivation of talents should begin with the cultivation of open and innovative talents, who know better than their teachers, the constant update of their consciousness to guide these talents to establish a scientific and correct outlook on life, the provision of a good environment for them to grow, the combination of education with the education for outstanding talents for every student, the development of good training objectives and training measures, as well as the creation of a different training mode, which would encourage talents to serve different areas and different levels and at any time, predicated on the needs of the society and the market. The training mode of talents is proportional to the type of trained talents; when the training mode of talents is different, the trained talents are different. The standardization and feasibility of the training mode indicate that the training mode is based on certain theories and ideas with a fixed frame or procedure for talent training; in addition, it also needs to be based on the society and the market while trying to formulate assessment measures for each of the link in the process of talent training, so as to ensure the quality of talent cultivation. Only in this manner, the obstacles that prevent the cultivation of foreign language talents in technical colleges and universities can be overcome, and innovative talents who are worthy of our time can be cultivated.

\section{Acknowledgments}

We would like to express our appreciation to a famous scholar, Gechuan Qian, who is the author of a book titled Discussion on Translation. Our heartfelt gratitude also goes to an unknown editor of a magazine titled United Front in Hunan, who narrated the story of a famous character and Changji Yang. We referred to both sources for the completion of this article.

\section{Disclosure statement}

The authors declare that there is no conflict of interest.

\section{References}

[1] An unknown Editor, 1993, Story of a Famous Character and Changji Yang, United Front in Hunan, 1993(5): 16.

[2] Qian G, 1980, Discussion on Translation, China Translation \& Publishing Corporation, Beijing, 7. 